\title{
Experimental study of the boron-containing mixtures burning rate
}

\author{
Yana Dubkova ${ }^{1, *}$, Alexander Zhukov ${ }^{1}$, Ilya Zhukov ${ }^{1,2}$, and Vladimir Promakhov ${ }^{2}$ \\ ${ }^{1}$ National Research Tomsk State University, 634050 Tomsk, Russia \\ ${ }^{2}$ Institute for Problems of Chemical and Energetic Technologies, 659300 Biysk, Russia
}

\begin{abstract}
The results of the experimental determination of the burning rate of boron-containing fuel mixtures in the pressure range $(0.1 \div 6) \mathrm{MPa}$ are presented. The results of a comparative analysis of the burning rate of samples with component different compositions are given.
\end{abstract}

\section{Introduction}

The design and development of advanced solid propellant systems used in the propulsion plants for various purposes, requires a detailed study of the basic properties of the new compositions. In particular, the use of a new generation of solid-fuel systems can provide increased specific impulse thrust propulsion to $(15 \div 20) \%$. One of the main energy characteristics of fuel systems, along with the heat of combustion, heat capacity and thermal conductivity, is the burning rate $[1,2]$. Despite the development of technologies for obtaining new materials currently, there are no experimental data on the basic functional properties of the new fuel systems depending on external dynamic and thermal effects. In this regard, actually creating a database on the properties of the new solid systems on the basis of experimental studies simulating real nature conditions [3].

This paper presents the results of experimental determination of the burning rate of the samples of the two groups of boron-containing fuel mixtures based on titanium, depending on external conditions.

\section{Materials and methods of the experimental research}

To determine the burning rate experimentally investigated two groups of boron-containing fuel mixtures $-\mathrm{P} 1$ and $\mathrm{P} 2$.

Examples of group P1 were made from a stoichiometric mixture of powders of titanium and boron amorphous ( 69 wt. \% Ti+31 wt. \% B) with inserted high-energy additives - fine aluminium powder $\left(d_{p} \sim 100 \mu \mathrm{m}\right)$. The data of raster electron microscopy (REM-images) of the original powders is shown in Fig. 1.

\footnotetext{
* Corresponding author: y.a.dubkova@niipmm.tsu.ru
} 


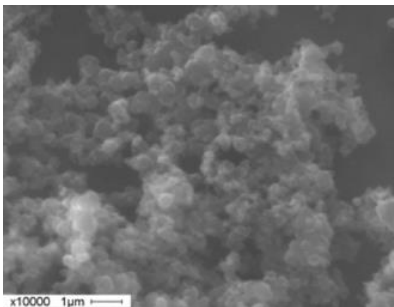

a

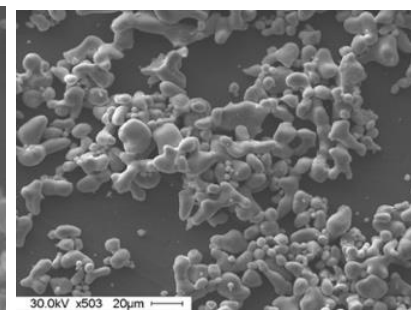

b

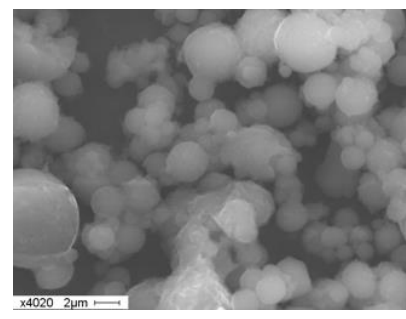

C

Fig. 1. REM-images of amorphous boron powder (a), of titanium powder type PTOM, $0-40 \mu \mathrm{m}$ (b) and of aluminium powder type ASD.

The content of the input aluminum powder, the minimum required to ensure sustainable combustion, was determined by the results of preliminary experimental studies [4] and was $(1.0 \div 5.0)$ wt. $\%$ in excess of the mass of a stoichiometric mixture of $\mathrm{Ti}+\mathrm{B}$. The tests were subjected to cylindrical specimens made by compacting mixtures of the initial powders. As a binder used was ultra-high molecular weight polyethylene (UHMWPE) [5] in the solid state in the form of spherical granules with a size of from 40 to 80 microns and polyvinyl alcohol (PVA) $\left(\mathrm{C}_{2} \mathrm{H}_{4} \mathrm{O}\right)_{\mathrm{x}}[6]$ in the form of a $3 \%$ aqueous solution.

Samples of group P2 were made by through passage pressing the mixture of powders with different content of oxidizer, metal fuel, catalysts, technological additives with a polymeric fuel-binder. The components of the compositions of boron-containing fuel mixtures of group P2 are given in Table. 1.

Table 1. The components of the compositions of boron-containing fuel mixtures of group P2.

\begin{tabular}{|c|c|c|c|c|c|}
\hline \multirow{2}{*}{ Components, wt. \% } & \multicolumn{5}{|c|}{ The fuel mixtures } \\
\cline { 2 - 6 } & 1 & 2 & 3 & 4 & 5 \\
\hline SKDM-80 & 14.8 & 13.6 & 11.0 & 11.8 & 16.0 \\
\hline Ammonium perchlorate & 70.2 & 71.4 & 74.0 & 73.2 & 69.0 \\
\hline $\mathrm{TiB}_{2}$ & 15.0 & - & - & - & - \\
\hline $\mathrm{AlB}_{2}$ & - & 15.0 & - & - & - \\
\hline $\mathrm{B}$ & - & - & 15.0 & - & - \\
\hline $\mathrm{AlB}_{12}$ & - & - & - & 15.0 & - \\
\hline $\mathrm{ASD}_{2}$ & - & - & - & - & 15.0 \\
\hline
\end{tabular}

Samples of boron-containing fuel mixtures of groups P1 and P2 were burned in the chamber at a constant pressure (Crawford Bomb) in an inert environment (argon). A series of experiments conducted while changing the pressure in the chamber in the range $(0.1 \div 6) \mathrm{MPa}$.

The burning rate of samples of boron-containing fuel mixtures of groups P1 and P2 were determined using high-speed digital video camera. Obtained in the combustion process of samples of the video files were processed using special software processing of video files by the "TimeLapse". The video frames of the typical experiments for samples of fuel mixtures of groups $\mathrm{P} 1$ and $\mathrm{P} 2$ are given in Fig. 2, 3. 


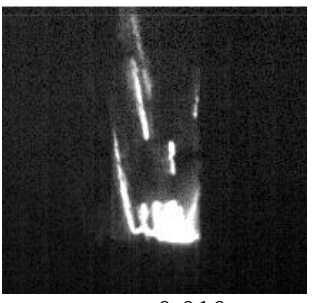

$t=0.010 \mathrm{~s}$

a

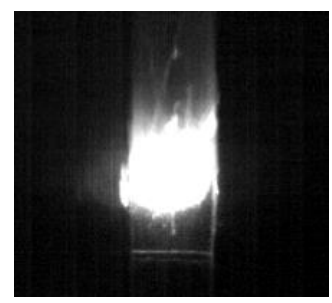

$t=0.055 \mathrm{~s}$

b

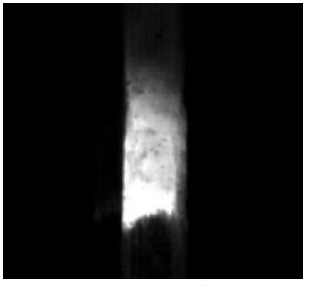

$t=0.108 \mathrm{~s}$

c

Fig. 2. Video frames of the combustion process of the sample of group P1.

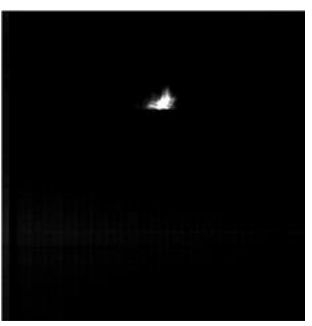

$t=0.015 \mathrm{~s}$

a

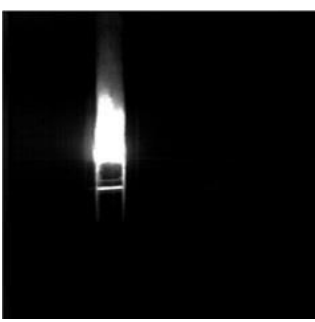

$t=0.055 \mathrm{~s}$

b

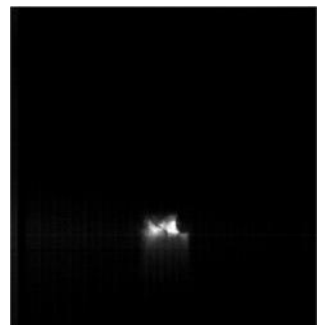

$t=0.18 \mathrm{~s}$

c

Fig. 3. Video frames of the combustion process of the sample of group P2.

The resulted frames illustrate the characteristic moments of the process, corresponding to the instant of ignition (Fig. 2, 3, a), to burning of the samples (Fig. 2, 3, b) and to extinction of the fuel mixtures (Fig. 2, 3, c).

For each composition were conducted at least three duplicate experiments.

The typical data of measurements of the burning rate of samples of group P2 in argon pressure $2 \mathrm{MPa}$, obtained on the basis of a series of experiments, are given in Table. 2.

Table 2. The data of measurements of the burning rate of samples of group P2.

\begin{tabular}{|c|c|c|c|c|c|}
\hline \multirow{2}{*}{$\begin{array}{c}\text { Experiment } \\
\text { number }\end{array}$} & \multicolumn{5}{|c|}{ The burning rate, $\mathbf{~ m m} / \mathbf{s}$} \\
\cline { 2 - 6 } & 1 & 2 & 3 & 4 & 5 \\
\hline 1 & $10.0 \pm 0.2$ & $24.7 \pm 0.2$ & $13.0 \pm 0.2$ & $30.0 \pm 0.2$ & $7.1 \pm 0.2$ \\
\hline 2 & $10.0 \pm 0.2$ & $24.4 \pm 0.2$ & $16.9 \pm 0.2$ & $26.8 \pm 0.2$ & $7.4 \pm 0.2$ \\
\hline 3 & $10.2 \pm 0.2$ & $24.5 \pm 0.2$ & $20.1 \pm 0.2$ & $26.0 \pm 0.2$ & $7.0 \pm 0.2$ \\
\hline
\end{tabular}

\section{Results of experimental study}

The visualization of the combustion process showed that the samples of boron-containing fuel mixtures with component different compositions are burning steadily in the pressure range $(0.1 \div 6) \mathrm{MPa}$ with the intense glow of the flame.

1. The burning rate of the samples of fuel mixtures of both groups in the pressure range under consideration does not depend on the pressure.

2. The burning rate of the samples of group P1 was $(100 \div 120) \mathrm{mm} / \mathrm{s}$ in the pressure range under consideration when aluminum powder content in the fuel mixture was at least 2.5 wt. $\%$.

3. The burning rate of samples of group $\mathrm{P} 2$ in the pressure range under consideration varied within $(6 \div 30) \mathrm{mm} / \mathrm{s}$ depending on the material composition of the fast-burning component in the fuel mixture (Table 1). 
4. It is obtained that the maximum of the burning rate of samples of group P2 is reached in the pressure range under consideration when the fuel mixture contains amorphous boron or aluminum polyboride (Table 2 ).

\section{Conclusions}

Burning rate of the two groups of fuel compositions was obtained experimentally. Maximum burning rate for samples of group P2 was observed on compositions containing amorphous boron. Burning rate of samples of group P1 amount to $(100 \div 120) \mathrm{mm} / \mathrm{s}$ and in the considered range of pressures $(0.1 \div 6) \mathrm{MPa}$ does not depend on external conditions. It can be concluded that the powder composition of group P1 has a higher burning rate and can be used to reinforce fuel pellets. Powder compositions of group P2 have high performance, and the burning rate does not depend on pressure, which gives reason to talk about the possibility of their use as high-energy materials.

The work was financially supported by the RFBR, research project No. 16-38-60028 mol a dk and with the financial support of the grant of the President of MK-837.2017.8 agreement $\mathrm{N}$ 14.Y30.17.837-MK.

\section{References}

1. H. Yaman, V. Celik, E. Degirmenci, Fuel, 115 (2014)

2. A. Dey, RSC Advances, 5 (2015)

3. N. Kubota, Propellants and explosives: thermochemical aspects of combustion (John Wiley \& Sons, London, 2015).

4. Y. Dubkova, A. Zhukov, MATEC Web Conf. 92, 01068 (2017)

5. S.S. Gabaliev, R.Z. Hairulin, V.P. Arhireev, Journal of Kazan University of Technology, $\mathbf{5 0}$ (2008)

6. I.P. Losev, E.B. Trostanskaya, The Chemistry synthetic polymer (Chemistry, Moscow, 1971) [In Russian] 